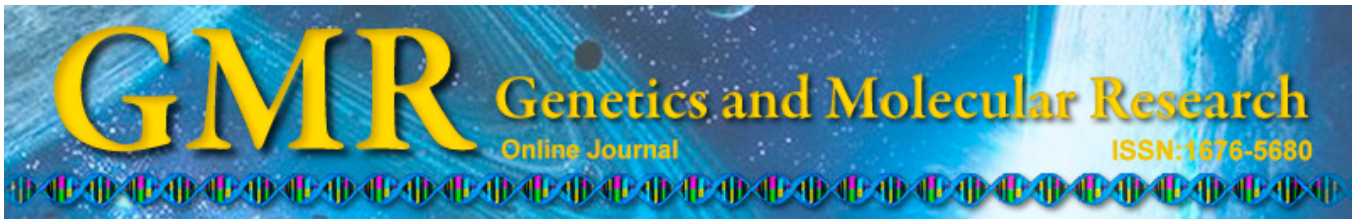

\title{
Comparative analysis of genetic diversity among species of Chrysanthemum and its related genera using inter-simple sequence repeat and sequence-related amplified polymorphism markers
}

\author{
X. Zhang ${ }^{1,2 *}$, F. Zhang ${ }^{1 *}$, H. Zhao ${ }^{3}$, Z. Guan ${ }^{1}$, S. Chen ${ }^{1}$, J. Jiang ${ }^{1}$, \\ W. Fang ${ }^{1}$ and F. Chen ${ }^{1}$ \\ ${ }^{1}$ College of Horticulture, Nanjing Agricultural University, \\ Nanjing, Jiangsu Province, China \\ ${ }^{2}$ College of Horticulture, Shanxi Agricultural University, \\ Taigu, Shanxi Province, China \\ ${ }^{3}$ College of Landscape Architecture, Zhejiang A \& F University, \\ Hangzhou, Zhejiang Province, China \\ *These authors contributed equally to this study. \\ Corresponding authors: W. Fang / F. Chen \\ E-mail: fangwm@njau.edu.cn / chenfd@njau.edu.cn
}

Genet. Mol. Res. 13 (4): 8469-8479 (2014)

Received September 26, 2013

Accepted February 17, 2014

Published October 20, 2014

DOI http://dx.doi.org/10.4238/2014.October.20.23

\begin{abstract}
In this study, inter-simple sequence repeats (ISSRs) and sequence-related amplified polymorphism (SRAP) were applied to assess the genetic diversity in 38 species of Chrysanthemum and related genera. A total of 204 and 567 bands were amplified by 24 ISSR and 25 SRAP primers, of which 196 (97\%) and 557 (99\%) were polymorphic, respectively. The ISSR-based genetic similarity ranged from 0.016 to 0.886 and averaged 0.201 , while the SRAP-based genetic similarity varied from 0.010 to 0.811 and averaged 0.122 . Both the ISSR and SRAP techniques revealed similar clustering patterns and
\end{abstract}


grouped species of Chrysanthemum and Ajania together. The results of principal coordinate analysis corroborated the unweighted pair group method with arithmetic average clustering. Additionally, results from ISSR and SRAP data were significantly correlated $(\mathrm{r}=0.89, \mathrm{P}<0.001)$. Knowledge about genetic diversity among species can aid the transfer of traits of interest from the wild into cultivated chrysanthemum in future distant interspecific breeding.

Key words: Chrysanthemum; Inter-simple sequence repeat; Related genera; Sequence-related amplified polymorphism; Genetic diversity

\section{INTRODUCTION}

Species of Chrysanthemum and related genera, the gene pool of cultivated chrysanthemum, possess great ornamental values and are therefore of great economic importance for commercial utilization. Moreover, some of the species are endowed with novel traits of horticultural interest and strong stress and disease resistance that are not present in chrysanthemum cultivars (Sun et al., 2010a; Deng et al., 2010, 2011, 2012). Hence, many new cultivars of chrysanthemum with improved target traits possibly will emerge once hybrid parents are expanded to wild species of Chrysanthemum and related genera. The future success of these events, however, depends on accurate information about the genetic diversity and relatedness among the species of Chrysanthemum and related genera. So far, considerable interest has focused on phylogenetics among species of Chrysanthemum and related genera (Bremer and Humphries, 1993; Watson et al., 2000, 2002; Kondo and El-Twab, 2002; Ohashi and Yonekura, 2004; Zhao et al., 2007, 2009, 2010a,b; Tang et al., 2009), yet their genetic relationship remains a concern.

Inter-simple sequence repeat (ISSR) and sequence-related amplified polymorphism (SRAP) have been recognized as useful molecular markers in cultivar identification, markerassisted selection, and other purposes including analyses of genetic diversity and delimitation across species or genera such as Celosia (Feng et al., 2009), Cynodon (Gulsen et al., 2009), Cucurbitaceae (Sikdar et al., 2010), Polygala (Lüdtke et al., 2010), and Solanum (Li et al., 2010). These studies have given useful clues to understand species or genera relationships that assist in implementing a sound breeding program. Recently, ISSR and SRAP have been used to characterize medicinal chrysanthemum (Shao et al., 2010), but no similar reports on genetic diversity among wild species of Chrysanthemum and related genera are available.

Here, we reported a comparison of the genetic diversity among species of Chrysanthemum and related genera using both ISSR and SRAP markers. The objectives of the study were to 1) reveal genetic diversity among species of Chrysanthemum and related genera using ISSR and SRAP markers, 2) compare different marker techniques, and 3) address the hybridization potential among species of Chrysanthemum and related genera.

\section{MATERIAL AND METHODS}

\section{Plant materials and DNA extraction}

The plant materials herein comprised 38 species of 10 genera, including 16 species of 
Chrysanthemum, seven species each of Ajania and Artemisia, two species of Tanacetum, and one species each of Glebionis, Coleostephus, Crossostephium, Leucanthemum, Nipponanthemum, and Argyranthemum (Table 1). All the materials were maintained at the Chrysanthemum Germplasm Resource Preserving Center, Nanjing Agricultural University, China.

Total genomic DNA was extracted from young leaves of each species according to the cetyltrimethylammonium bromide-based method that was described by Murray and Thompson (1980) with minor modifications. DNA concentrations were $25 \mathrm{ng} / \mu \mathrm{L}$ for polymerase chain reaction (PCR) analysis and were determined by comparison with known concentrations of Lambda DNA.

Table 1. Thirty eight species of Chrysanthemum and related genera, along with their resource and distribution, used for genotyping analysis in this study.

\begin{tabular}{|c|c|c|c|c|}
\hline No. & Code & Species & Collection site & Distribution \\
\hline 1 & $\mathrm{C} 1$ & Chrysanthemum zawadskii & Huangshan, Anhui, China & Eastern Europe through Russia to China and Japan \\
\hline 2 & $\mathrm{C} 2$ & Chrysanthemum japonense & Kyushu, Japan & Japan \\
\hline 3 & $\mathrm{C} 3$ & Chrysanthemum indicum & Nanjing, Jiangsu, China & Eastern Asia \\
\hline 4 & $\mathrm{C} 4$ & Chrysanthemum lavandulifolium & Beijing, China & China \\
\hline 5 & $\mathrm{C} 5$ & Chrysanthemum nankingense & Nanjing, Jiangsu, China & China \\
\hline 6 & C6 & Chrysanthemum dichrum & Neiqiu, Hebei, China & China \\
\hline 7 & $\mathrm{C} 7$ & Chrysanthemum vestitum & Tianzhushan, Anhui, China & China \\
\hline 8 & $\mathrm{C} 8$ & Chrysanthemum boreale & Honshu, Japan & China, Korea, Japan \\
\hline 9 & C9 & Chrysanthemum japonicum & Honshu, Japan & Japan \\
\hline 10 & $\mathrm{C} 10$ & Chrysanthemum hypargyrum & Taibaishan, Shaanxi, China & China \\
\hline 11 & $\mathrm{C} 11$ & Chrysanthemum yoshinaganthum & Shikoku, Japan & Japan \\
\hline 12 & $\mathrm{C} 12$ & Chrysanthemum okiense & West Honshu, Japan & Japan \\
\hline 13 & $\mathrm{C} 13$ & Chrysanthemum ornatum & Kyushu, Japan & Japan \\
\hline 14 & $\mathrm{C} 14$ & Chrysanthemum crassum & Kyushu, Japan & Japan \\
\hline 15 & $\mathrm{C} 15$ & Chrysanthemum yezoense & North Honshu, Japan & Japan \\
\hline 16 & $\mathrm{C} 16$ & Chrysanthemum weyrichi & Nikko, Japan & Far East, Japan \\
\hline 17 & $\mathrm{Aj} 1$ & Ajania pacificum & Tsukuba, Japan & China (Taiwan) \\
\hline 18 & $\mathrm{Aj} 2$ & Ajania shiwogiku var. kinokuniense & Tsukuba, Japan & Japan \\
\hline 19 & $\mathrm{Aj} 3$ & Ajania myriantha & Jinchuan, Sichuan, China & China \\
\hline 20 & $\mathrm{Aj} 4$ & Ajania remotipinna & Taibaishan, Shaanxi, China & China \\
\hline 21 & $\mathrm{Aj} 5$ & Ajania fruticulosa & Helanshan, Ningxia, China & China, Central Asia, Mongolia, Eastern Siberia \\
\hline 22 & Aj6 & Ajania salicifolia & Jingyuan, Gansu, China & China \\
\hline 23 & $\mathrm{Aj} 7$ & Ajania tripinnatisecta & Hongyuan, Sichun, China & China \\
\hline 24 & Ar1 & Artemisia sericea & Nanjing, Jiangsu, China & China, Russia, Siberia, Mongolia \\
\hline 25 & Ar2 & Artemisia scoparia & Nanjing, Jiangsu, China & China, Mongolia, Russia, Japan, Korea, India, Europe \\
\hline 26 & Ar3 & Artemisia japonica & Nanjing, Jiangsu, China & Asia \\
\hline 27 & Ar4 & Artemisia vulgaris & Nanjing, Jiangsu, China & Eurasia, North America, Northern Africa \\
\hline 28 & Ar5 & Artemisia abrotanum & Tsukuba, Japan & North America \\
\hline 29 & Ar6 & Artemisia absinthium & Tsukuba, Japan & North America \\
\hline 30 & $\operatorname{Ar} 7$ & Artemisia sieversiana & Yuntaishan, Henan, China & China, Korea, Japan, Mongolia \\
\hline 31 & $\mathrm{~T} 1$ & Tanacetum parthenium & Chiba, Japan & Cultivated \\
\hline 32 & $\mathrm{~T} 2$ & Tanacetum vulgare $\mathrm{L}$. & Tsukuba, Japan & Europe, Asia \\
\hline 33 & G & Glebionis coronaria & Nanjing, Jiangsu, China & Cultivated \\
\hline 34 & $\mathrm{Co}$ & Coleostephus multicaulis & Dafeng City, Jiangsu, China & China \\
\hline 35 & $\mathrm{Cr}$ & Crossostephium chinense & Xiamen, Fujian, China & China, Japan, Philippines \\
\hline 36 & $\mathrm{~L}$ & Leucanthemum vulgare & Beijing, China & Cultivated \\
\hline 37 & $\mathrm{~N}$ & Nipponanthemum nipponicum & Chiba, Japan & Japan \\
\hline 38 & $\mathrm{~A}$ & Argyranthemum frutescens & Tokyo, Japan & Cultivated \\
\hline
\end{tabular}

\section{ISSR and SRAP profiling}

A set of 77 ISSR primers and 23 SRAP primers ( 9 forward and 14 reverse primers) 
was synthesized by Invitrogen (Shanghai, China). All primers were initially used to detect polymorphism between five arbitrarily selected species, and only those primers generating reproducible polymorphisms were applied to all 38 species for further polymorphic analysis (Table 2).

\begin{tabular}{|c|c|c|c|}
\hline ISSR primer & Primer sequence $\left(5^{\prime} \rightarrow 3^{\prime}\right)$ & SRAP primer* & Primer sequence $\left(5^{\prime} \rightarrow 3^{\prime}\right)$ \\
\hline ISSR04 & ACACACACACACACACAG & Me13 & TGAGTCCAAACCGGTAA \\
\hline ISSR05 & ACACACACACACACACAT & Me17 & AGCGAGCAAGCCGGTGG \\
\hline ISSR08 & ATGATGATGATGATGATG & Me19 & CAAATGTGAACCGGATA \\
\hline ISSR12 & GAGGAGGAGGAGGAGGAG & Me20 & GAGTATCAACCCGGATT \\
\hline ISSR17 & GACAGACAGACAGACA & $\mathrm{Me} 21$ & GTACATAGAACCGGAGT \\
\hline ISSR22 & ACACACACACACACACAA & Me22 & TACGACGAATCCGGACT \\
\hline ISSR23 & ACACACACACACACACTA & $\mathrm{Me} 23$ & CACAGTCATGCCGGAAT \\
\hline ISSR24 & ACACACACACACACACTC & Me24 & GACCAGTAAACCGGATG \\
\hline ISSR32 & AGAGAGAGAGAGAGAGAC & Me25 & CAGGACTAAACCGGATA \\
\hline ISSR33 & AGAGAGAGAGAGAGAGTA & Em1 & GACTGCGTACGAATTAAT \\
\hline ISSR35 & AGAGAGAGAGAGAGAGTA & Em2 & GACTGCGTACGAATTTGC \\
\hline ISSR42 & ACACACACACACACACCG & Em4 & GACTGCGTACGAATTTGA \\
\hline ISSR43 & ACACACACACACACACCT & Em5 & GACTGCGTACGAATTAAC \\
\hline ISSR48 & TGTGTGTGTGTGTGTGAA & Em6 & GACTGCGTACGAATTGCA \\
\hline ISSR49 & TGTGTGTGTGTGTGTGAC & Em7 & GACTGCGTACGAATTATG \\
\hline ISSR52 & TGTGTGTGTGTGTGTGGA & Em8 & GACTGCGTACGAATTAGC \\
\hline ISSR53 & TGTGTGTGTGTGTGTGGC & Em9 & GACTGCGTACGAATTACG \\
\hline ISSR57 & AGAGAGAGAGAGAGAGTG & Em10 & GACTGCGTACGAATTTAG \\
\hline ISSR58 & AGAGAGAGAGAGAGAGGA & Em11 & GACTGCGTACGAATTTCG \\
\hline ISSR59 & AGAGAGAGAGAGAGAGGC & Em14 & GACTGCGTACGAATTCAG \\
\hline ISSR61 & AGAGAGAGAGAGAGAGGT & Em15 & GACTGCGTACGAATTCTG \\
\hline ISSR62 & AGAGAGAGAGAGAGAGCA & Em16 & GACTGCGTACGAATTCGG \\
\hline ISSR64 & AGAGAGAGAGAGAGAGCG & Em19 & TGTGGTCCGCAAATTTAG \\
\hline ISSR75 & AGTGAGTGAGTGAGTG & & \\
\hline
\end{tabular}

$* \mathrm{Me}=$ forward primers; $\mathrm{Em}=$ reverse primers.

For ISSR analysis, the PCR procedures followed Zhang et al. (2010), and PCR products were separated by electrophoresis on $1.5 \%$ agarose gels run at $100 \mathrm{~V}$ for $50 \mathrm{~min}$ in $1 \mathrm{X}$ Tris-acetate-ethylenediaminetetraacetic acid buffer and visualized by ethidium bromide staining. For SRAP analysis, both PCR and electrophoretic procedures were carried out as described by Zhang et al. (2011).

\section{Data scoring and statistical analysis}

Amplified bands were scored $1 / 0$ as presence/absence of homologous bands across the 38 species for each primer or primer combination. Dendrograms were constructed based on Nei's genetic distance using unweighted pair group method with arithmetic average (UPGMA) with the SAHN module of NTSYS-pc 2.2 (Rohlf, 2005). The COPH and MXCOP modules were used to determine the goodness-of-fit between the cluster analysis and original matrix. The principal coordinate analysis ( $\mathrm{PCoA}$ ) was conducted to construct a two-dimensional array of eigenvectors using the DCENTER and EIGEN modules of NTSYS-pc. Finally, the Mantel $Z$-test (Mantel, 1967) was used with 1000 permutations to determine the significance level between the ISSR- and SRAP-based similarity matrices. 


\section{RESULTS}

\section{Molecular marker analysis}

A set of 24 primers of the 77 total ISSR primers were selected. These produced a total of 204 bands across the 38 species of Chrysanthemum and related genera (Table 3 ). The number of amplified bands per primer ranged from 4 to 14 with an average of 8.5. Of the 204 scored bands, 196 were polymorphic (97\%), varying from five (ISSR35 and ISSR43) to 12 (ISSR57) polymorphic bands per primer and a mean of 8.2 polymorphic bands (Table 3 ). A profile obtained from ISSR23 was shown in Figure 1A.

\begin{tabular}{|c|c|c|c|c|c|c|c|}
\hline Primer & Bands scored & PB & PPB (\%) & Primer & Bands scored & PB & PPB (\%) \\
\hline ISSR04 & 13 & 12 & 92.0 & ISSR48 & 7 & 7 & 100.0 \\
\hline ISSR05 & 6 & 6 & 100.0 & ISSR49 & 11 & 10 & 91.0 \\
\hline ISSR08 & 10 & 10 & 100.0 & ISSR52 & 6 & 6 & 100.0 \\
\hline ISSR12 & 8 & 8 & 100.0 & ISSR53 & 7 & 7 & 100.0 \\
\hline ISSR17 & 8 & 8 & 100.0 & ISSR57 & 14 & 12 & 86.0 \\
\hline ISSR22 & 9 & 8 & 89.0 & ISSR58 & 8 & 8 & 100.0 \\
\hline ISSR23 & 12 & 11 & 92.0 & ISSR59 & 9 & 9 & 100.0 \\
\hline ISSR24 & 7 & 7 & 100.0 & ISSR61 & 8 & 8 & 100.0 \\
\hline ISSR32 & 10 & 10 & 100.0 & ISSR62 & 4 & 4 & 100.0 \\
\hline ISSR33 & 13 & 12 & 92.0 & ISSR64 & 6 & 6 & 100.0 \\
\hline ISSR35 & 5 & 5 & 100.0 & ISSR75 & 7 & 7 & 100.0 \\
\hline ISSR42 & 11 & 10 & 91.0 & Total & 204 & 196 & - \\
\hline ISSR43 & 5 & 5 & 100.0 & Average & 8.5 & 8.2 & 97.0 \\
\hline
\end{tabular}

$\mathrm{PB}=$ polymorphic bands; $\mathrm{PPB}=$ percentage of polymorphic bands among the total scored bands.

A total of 118 SRAP primer combinations derived from 9 forward and 14 reverse primers were first screened for polymorphism. Only 25 primer combinations that generated informative bands were chosen for genotyping analysis. As a result, a total of 567 bands were produced, with an average of 21.8 per primer combination. Of the 567 amplified bands, 557 were polymorphic $(99.0 \%)$. The number of polymorphic bands for individual primer combinations ranged between $11(\mathrm{Me} 21 \mathrm{Em} 4)$ and $36(\mathrm{Me} 21 \mathrm{Em} 15)$ and averaged 31 (Table 4). A profile obtained from Me25Em19 was shown in Figure 1B.

\section{Cluster analysis}

Using the ISSR binary matrix, the genetic similarities based on Jaccard's coefficient among all species ranged from 0.016 to 0.886 , with a mean of 0.201 . For the ISSR-based dendrogram, cophenetic correlation was calculated at $\mathrm{r}=0.94$, which corresponded to a very good fit. The dendrogram grouped all species into two major clusters and four separate clades (Figure 2A). Cluster I included all species of Chrysanthemum and Ajania but Ajania tripinnatisecta and Crossostephium chinense. The other species of related genera were grouped into cluster II, except that Artemisia vulgaris, Artemisia absinthium, Artemisia sieversiana, and Argyranthemum frutescens clustered as four separate clades.

The SRAP-based genetic similarity varied from 0.010 to 0.811 and had an average of 0.122 . The UPGMA dendrogram based on Nei's genetic distance for the 38 species was 
depicted in Figure 2B. The cophenetic correlation was estimated at 0.91, indicating a good fit between the dendrogram and the original matrix. The dendrogram grouped the 38 species into four major clusters. Cluster a consisted of all species of Chrysanthemum and species of Ajania excluding Ajania salicifolia and Ajania tripinnatisecta. The other species of related genera were grouped together in cluster b, and Crossostephium chinense and Artemisia sieversiana were grouped as two separate clusters, $\mathrm{c}$ and $\mathrm{d}$.



Figure 1. Inter-simple sequence repeat (ISSR) profiles obtained from ISSR 23 (A) and sequence-related amplified polymorphism (SRAP) profiles obtained from Me25Em19 (B) of the 38 species of Chrysanthemum and related genera. Lanes $1-38=$ species listed in Table 1 . Lane $M=$ DNA marker ladder.

Table 4. Amplification results of sequence-related amplified polymorphism (SRAP) analysis.

\begin{tabular}{|c|c|c|c|c|c|c|c|}
\hline Primer combination & Bands scored & PB & PPB (\%) & Primer combination & Bands scored & PB & PPB (\%) \\
\hline Me13Em4 & 18 & 18 & 100.0 & Me22Em7 & 19 & 19 & 100.0 \\
\hline Me17Em9 & 19 & 19 & 100.0 & $\mathrm{Me} 22 \mathrm{Em} 8$ & 28 & 28 & 100.0 \\
\hline Me19Em15 & 14 & 14 & 100.0 & Me22Em9 & 29 & 27 & 93.0 \\
\hline $\mathrm{Me} 20 \mathrm{Em} 4$ & 31 & 29 & 94.0 & Me22Em11 & 31 & 31 & 100.0 \\
\hline Me20Em5 & 15 & 15 & 100.0 & Me22Em14 & 22 & 22 & 100.0 \\
\hline $\mathrm{Me} 20 \mathrm{Em} 10$ & 35 & 35 & 100.0 & Me22Em15 & 19 & 19 & 100.0 \\
\hline $\mathrm{Me} 21 \mathrm{Em} 1$ & 19 & 18 & 95.0 & Me23Em5 & 12 & 12 & 100.0 \\
\hline $\mathrm{Me} 21 \mathrm{Em} 2$ & 16 & 16 & 100.0 & Me23Em6 & 34 & 33 & 97.0 \\
\hline $\mathrm{Me} 21 \mathrm{Em} 4$ & 11 & 11 & 100.0 & $\mathrm{Me} 22 \mathrm{Em} 5$ & 19 & 19 & 100.0 \\
\hline Me21Em6 & 17 & 17 & 100.0 & $\mathrm{Me} 24 \mathrm{Em} 15$ & 25 & 24 & 96.0 \\
\hline Me21Em11 & 16 & 16 & 100.0 & Me24Em16 & 13 & 13 & 100.0 \\
\hline Me21Em15 & 36 & 35 & 97.0 & $\mathrm{Me} 25 \mathrm{Em} 19$ & 29 & 29 & 100.0 \\
\hline Me22Em1 & 23 & 22 & 96.0 & Total & 567 & 557 & - \\
\hline Me22Em4 & 17 & 16 & 94.0 & Average & 21.8 & 21.0 & 99.0 \\
\hline
\end{tabular}

$\mathrm{PB}=$ polymorphic bands; $\mathrm{PPB}=$ percentage of polymorphic bands among the total scored bands.

\section{PCoA and Mantel test}

Two-dimensional plots of PCoA according to the ISSR- and SRAP-based genetic distance, respectively, were shown in Figure $3 \mathrm{~A}$ and B. PCoA results generally reinforced the 
dendrograms. The first two ordinates explained 39.6 and $41.7 \%$ of the total variations for ISSR and SRAP, respectively. By the Mantel test, a significant correlation $(\mathrm{r}=0.89, \mathrm{P}<0.001)$ was observed between the ISSR- and SRAP-based Jaccard's similarity matrices, implying that the two marker systems have a linear relationship with a high determination coefficient $\left(R^{2}=0.79\right)$.

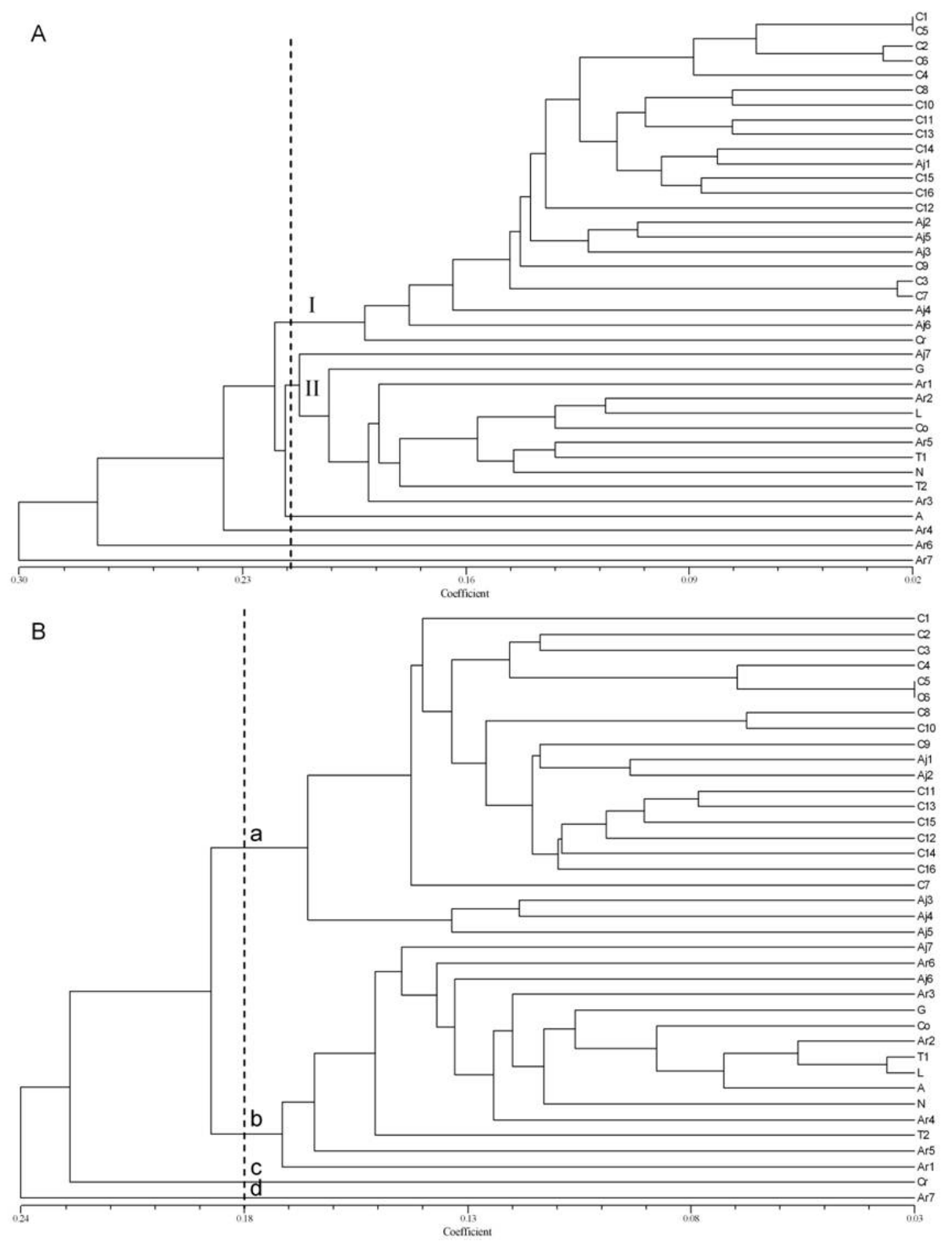

Figure 2. Unweighted pair group method with arithmetic average (UPGMA) dendrogram using ISSR (A) and SRAP (B) of 38 species of Chrysanthemum and related genera. The codes listed on the right of the dendrograms refer to those listed in Table 1. 

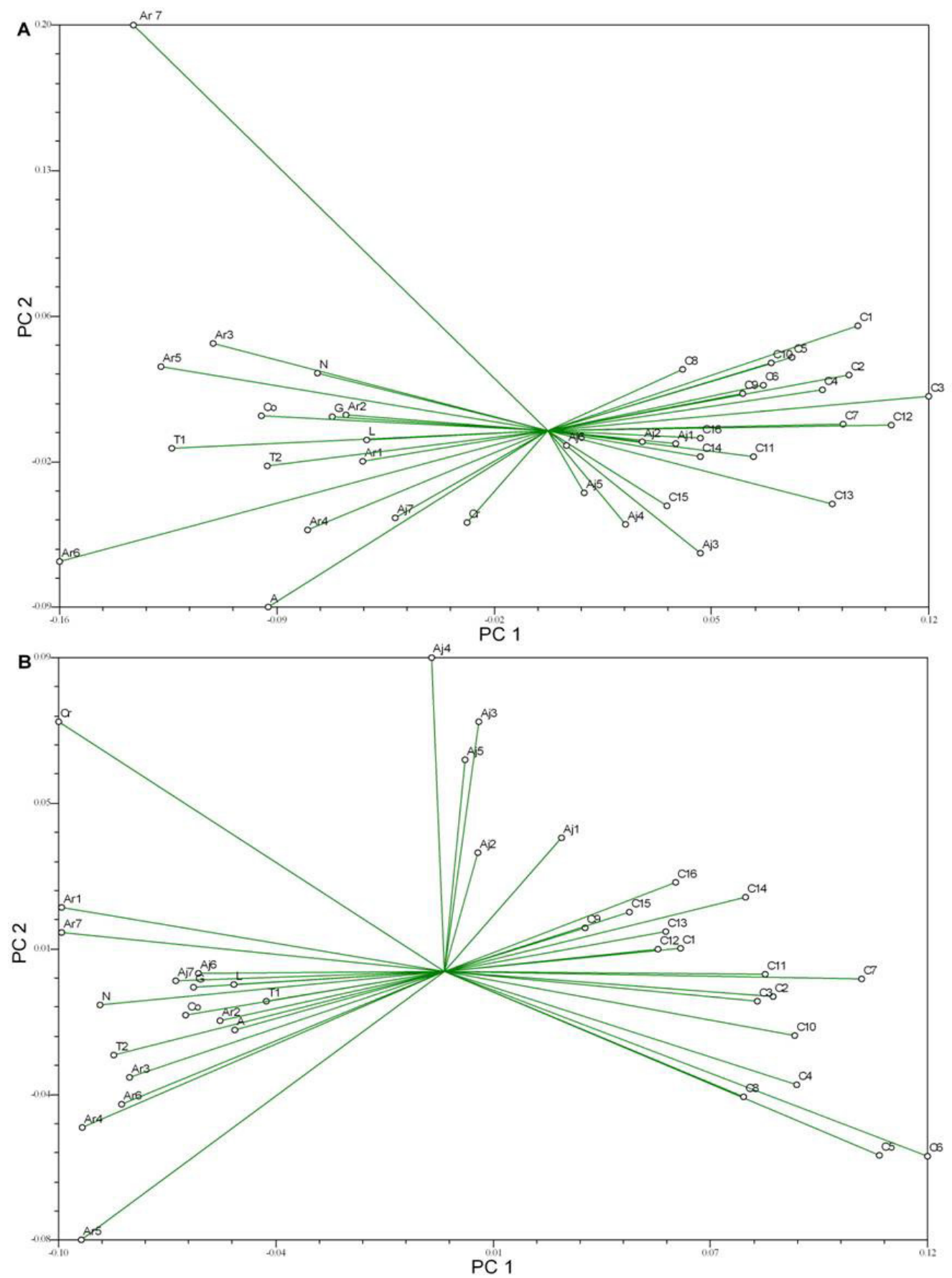

Figure 3. Two-dimensional plot with vectors of principal coordinate analysis (PCoA) of 38 species of Chrysanthemum and related genera using ISSR (A) and SRAP (B) markers. The codes listed in the Figure refer to those listed in Table 1. 


\section{DISCUSSION}

Complete information about genetic diversity and genetic relationships enable effective conservation and sound utilization of crop germplasm. In this study, ISSR and SRAP markers were applied to assess the level and pattern of genetic diversity in 38 species of Chrysanthemum and related genera. Both markers exhibited $>95 \%$ polymorphism and relatively low genetic similarity, indicative of the wide genetic variability among different species of Chrysanthemum and related genera. ISSR and SRAP markers have been widely used to estimate genetic diversity in many crops. Budak et al. (2004) and Fu et al. (2008) reported that SRAP was more informative than ISSR for assessing genetic diversity, but Wang et al. (2012) reported that ISSR was more effective than SRAP for assessing the genetic variation of goat's rues. Song et al. (2010) and Shao et al. (2010) observed that both markers were similarly effective. In this study, SRAP showed more polymorphic bands and lower derived genetic similarity than ISSR. However, a significant correlation $(\mathrm{r}=0.89, \mathrm{P}<0.001)$ was observed between the similarity matrices obtained based on ISSR and SRAP data. Therefore, the results demonstrated that both ISSR and SRAP were effective and reliable for accurately assessing the level of genetic diversity among species of Chrysanthemum and related genera.

Previous studies indicated that many methods, including internal transcribed spacer and intergenic spacer sequences and amplified fragment length polymorphism markers failed to define the boundary between Chrysanthemum and Ajania (Bremer and Humphries, 1993; Zhao et al., 2010a,b). In this study, UPGMA cluster analyses grouped species of Chrysanthemum and most species of Ajania together, suggesting that the species of the two genera were more closely related than other related genera. However, the clustering pattern of species within the cluster was not clear, and neither ISSR nor SRAP markers could distinguish species of Chrysanthemum and Ajania. In addition, most species of Artemisia clustered separately, revealing that the species of Artemisia might have a monophyletic origin.

PCoA is one of multiple approaches for grouping that is based on similarity coefficients or variance-covariance among the traits of the entries. In this study, the PCoA results generally agreed with those of UPGMA clustering. PCoA sometimes revealed more informative groupings. For instance, in this study, the SRAP-based PCoA unveiled a more unequivocal boundary between Chrysanthemum and Ajania than the SRAP-based UPGMA clustering.

Species of Chrysanthemum and related genera possess excellent genes governing desirable horticultural traits and some tolerance traits that do not appear in cultivated chrysanthemums. The transfer of these excellent genes to cultivated chrysanthemums would be useful to improve cultivated chrysanthemums. Fortunately, several studies have shown the cross compatibility between cultivated chrysanthemums and species of Chrysanthemum and related genera (Fukai et al., 2000; Sun et al., 2010b), Thus far, potentially useful $\mathrm{F}_{1}$ hybrids between cultivated chrysanthemums and species of Chrysanthemum and related genera have been produced through inter-specific or inter-generic hybridization with embryo rescue (Watanabe, 1977; Furuta et al., 2004). Recently, Deng et al. (2010, 2012) transferred resistance to aphid and Alternaria leaf spot from Artemisia vulgaris to cultivated chrysanthemums, and the same authors obtained some $\mathrm{F}_{1}$ hybrids with enhanced cold tolerance through the hybridization of cultivated chrysanthemum and Ajania przewalskii (Deng et al., 2011). Some ornamentally important traits, as well as traits of heat and drought tolerance, were also transferred to chrysanthemum by other authors (Zhao et al., 2007; Sun et al., 2010a; Cheng et al., 2011). 
This suggests that the transfer of desirable traits from Chrysanthemum and related genera to commercially cultivated chrysanthemums through distant hybridization makes the improved chrysanthemum cultivars possible. In this study, considerable genetic diversity and relatedness were observed by both ISSR and SRAP. This suggests that distant hybridization between species grouped in the same cluster is likely to be successful in future breeding programs.

\section{ACKNOWLEDGMENTS}

Research supported by the Fundamental Research Funds for the Central Universities (\#KYTZ201401), the "863" Project of Ministry of Science and Technology of the People's Republic of China (\#2011AA100208), the Science and Technology Program of Jiangsu Province (\#BE2012350), the Program for New Century Excellent Talents in University of Chinese Ministry of Education (Grant \#NCET-12-0890).

\section{REFERENCES}

Bremer K and Humphries C (1993). Generic monograph of the Asteraceae-Anthemideae. Bul. Nat. Hist. Mus. Bot. 23: 71-177.

Budak H, Shearman RC, Parmaksiz I and Dweikat I (2004). Comparative analysis of seeded and vegetative biotype buffalograsses based on phylogenetic relationship using ISSRs, SSRs, RAPDs, and SRAPs. Theor. Appl. Genet. 109: 280-288.

Cheng X, Chen S, Chen F, Deng Y, et al. (2011). Creating novel chrysanthemum germplasm via interspecific hybridization and backcrossing. Euphytica 177: 45-53.

Deng Y, Chen S, Chang Q, Wang H, et al. (2012). The chrysanthemum x Artemisia vulgaris intergeneric hybrid has better rooting ability and higher resistance to alternaria leaf spot than its chrysanthemum parent. Sci. Hortic. 134: 185-190.

Deng Y, Chen S, Lu A, Chen F, et al. (2010). Production and characterisation of the intergeneric hybrids between Dendranthema morifolium and Artemisia vulgaris exhibiting enhanced resistance to chrysanthemum aphid (Macrosiphoniella sanbourni). Planta 231: 693-703.

Deng Y, Chen S, Chen F, Cheng X, et al. (2011). The embryo rescue derived intergeneric hybrid between chrysanthemum and Ajania przewalskii shows enhanced cold tolerance. Plant Cell Rep. 30: 2177-2186.

Feng N, Xue Q, Guo Q, Zhao R, et al. (2009). Genetic diversity and population structure of Celosia argentea and related species revealed by SRAP. Biochem. Genet. 47: 521-532.

Fu X, Ning G, Gao L and Bao M (2008). Genetic diversity of Dianthus accessions as assessed using two molecular marker systems (SRAPs and ISSRs) and morphological traits. Sci. Hortic. 117: 263-270.

Fukai S, Nagira T and Goi M (2000). Cross compatibility between chrysanthemum (Dendranthema grandiflorum) and Dendranthema species native to Japan. Acta Hortic. 508: 337-340.

Furuta H, Shinoyama H, Nomura Y, Maeda M, et al. (2004). Production of intergeneric somatic hybrids of chrysanthemum [Dendranthema x grandiflorum (Ramat.) Kitamura] and wormwood (Artemisia sieversiana J. F. Ehrh. ex. Willd) with rust (Puccinia horiana Henning) resistance by electrofusion of protoplasts. Plant Sci. 166: 695-702.

Gulsen O, Sever-Mutlu S, Mutlu N, Tuna M, et al. (2009). Polyploidy creates higher diversity among Cynodon accessions as assessed by molecular markers. Theor. Appl. Genet. 118: 1309-1319.

Kondo K and El-Twab MHA (2002). Analysis of inter- and intra-generic relationships sensu stricto among the members of Chrysanthemum sensu lato by using fluorescent in situ hybridization. Chromosome Sci. 6: 87-100.

Li H, Chen H, Zhuang T and Chen J (2010). Analysis of genetic variation in eggplant and related Solanum species using sequence-related amplified polymorphism markers. Sci. Hortic. 125: 19-24.

Lüdtke R, Agostini G, Miotto STS and Souza-Chies TT (2010). Characterizing Polygala L. (Polygalaceae) species in southern Brazil using ISSR. Plant Mol. Biol. Rep. 28: 317-323.

Mantel N (1967). The detection of disease clustering and a generalized regression approach. Cancer Res. 27: 209-220.

Murray MG and Thompson WF (1980). Rapid isolation of high molecular weight plant DNA. Nucleic Acids Res. 8: 43214325.

Ohashi H and Yonekura K (2004). New combinations in Chrysanthemum (Compositae-Anthemideae) of Asia with a list of Japanese species. J. Jpn. Bot. 79: 186-195. 
Rohlf FJ (2005). NTSYS-pc: Numerical Taxonomy and Multivariate Analysis System. Version 2.2. Exeter Software. Setauket, New York.

Shao Q, Guo Q, Deng Y and Guo H (2010). A comparative analysis of genetic diversity in medicinal Chrysanthemum morifolium based on morphology, ISSR and SRAP markers. Biochem. Systemat. Ecol. 38: 1160-1169.

Sikdar B, Bhattacharya M, Mukherjee A, Banerjee A, et al. (2010). Genetic diversity in important members of Cucurbitaceae using isozyme, RAPD and ISSR markers. Biol. Plant. 54: 135-140.

Song Z, Li X, Wang H and Wang J (2010). Genetic diversity and population structure of Salvia miltiorrhiza Bge in China revealed by ISSR and SRAP. Genetica 138: 241-249.

Sun C, Chen F, Teng N, Liu Z, et al. (2010a). Interspecific hybrids between Chrysanthemum grandiflorum (Ramat.) Kitamura and C. indicum (L.) Des Moul. and their drought tolerance evaluation. Euphytica 174: 51-60.

Sun C, Chen F, Teng N, Liu Z, et al. (2010b). Factors affecting seed set in the crosses between Dendranthema grandiflorum (Ramat.) Kitamura and its wild species. Euphytica 171: 181-192.

Tang F, Chen F, Chen S, Teng N, et al. (2009). Intergeneric hybridization and relationship of genera within the tribe Anthemideae Cass. [I. Dendranthema crassum (Kitam.) Kitam. x Crossostephium chinense (L.) Makino]. Euphytica 169: 133-140.

Wang Z, Wang J, Wang X, Gao H, et al. (2012). Assessment of genetic diversity in Galega officinalis L. using ISSR and SRAP markers. Genet. Resour. Crop Evol. 59: 865-873.

Watanabe K (1977). Successful ovary culture and production of F1 hybrids and androgenic haploids in Japanese Chrysanthemum species. J. Hered. 68: 317-320.

Watson LE, Evans TM and Boluarte T (2000). Molecular phylogeny and biogeography of tribe anthemideae (Asteraceae), based on chloroplast gene ndhF. Mol. Phylogenet. Evol. 15: 59-69.

Watson LE, Bates PL, Evans TM, Unwin MM, et al. (2002). Molecular phylogeny of subtribe Artemisiinae (Asteraceae), including Artemisia and its allied and segregate genera. BMC Evol. Biol. 2: 17.

Zhang F, Chen S, Chen F, Fang W, et al. (2010). A preliminary genetic linkage map of chrysanthemum (Chrysanthemum morifolium) cultivars using RAPD, ISSR and AFLP markers. Sci. Hortic. 125: 422-428.

Zhang F, Chen S, Chen F, Fang W, et al. (2011). SRAP-based mapping and QTL detection for inflorescence-related traits in chrysanthemum (Dendranthema morifolium). Mol. Breed. 27: 11-23.

Zhao H, Chen F, Chen S, Wu G, et al. (2010a). Intergeneric phylogenetic relationship of Dendranthema (DC.) Des Moul., Ajania Poljakov and their allies based on amplifiead fragment length polymorphism. Sci. Agric. Sin. 43: 1302-1313.

Zhao H, Miao H, Wu G, Chen F, et al. (2010b). Molecular phylogeny of Chrysanthemum, Ajania and its allies (Anthemideae, Asteraceae) as inferred from nuclear ribosomal ITS and chloroplast trnL-F IGS sequences. Plant Syst. Evol. 284: 153-169.

Zhao H, Chen F, Guo W, Miao H, et al. (2007). Intergeneric hybrid of Dendranthema x grandiflorum "Aoyunhuoju" and Ajania pacifica and its taxonomic implications. Acta Phytotaxon. Sin. 45: 661-669.

Zhao H, Liu Z, Hu X, Yin J, et al. (2009). Chrysanthemum genetic resources and related genera of Chrysanthemum collected in China. Genet. Resour. Crop Evol. 56: 937-946. 